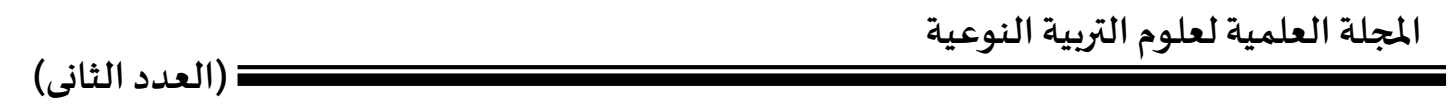

\title{
Effect of some plant extracts on blood glucose and other biological parameters of type 2 diabetic patients.
}

\author{
Hamdia Ahmed Helal; MaysaAbd-Elnaby El-Gonimy and Mohamed A. Elsaadany \\ Nutrition and Food Science Department, Faculty of Home Economics,Menofia \\ University.
}

\begin{abstract}
$\underline{\text { Abstract }}$
Diabetes mellitus is a common chronic disease affecting millions of people worldwide. It characterized by chronic hyperglycemia due to relative or absolute lack of insulin or its actions. Traditional treatmentsare still limited to achieve the normal blood glucose in many patients. Searching for new, safe and effective hypoglycemic drugs or herbs for diabetic patients are needed. Therefore, the aim of this study was to investigate the aqueous extract of Nigella sativa seeds (black seed) and Salvia officinalis (Sage) as an adjuvant therapy in patients with diabetes mellitus type 2 in addition to their anti-diabetic medications. A total of 16 patients were divided randomly into two groups. Capsules containing dried aqueous extract Nigella sativa andSalvia officinalis were administered orally in a dose of $200 \mathrm{mg}$ twice/day for ten days. Their effect on patients was assessed through measurement of fasting blood glucose (FBG),frequency of urination, Glutamic-Oxaloacetic Transaminase (GOT) and Glutamic-Pyruvic Transaminase (GPT) after 0, 5 and 10 days. Results showed that Nigella sativa caused significant reduction on FBG and urination after 5 and 10 days. Liver function including GOT and GPT showed also significant attenuation after 10 days.On the other hand Salvia officinalisdidn't show significant effects on any parameters except of reduction on urination after 10 days. In Conclusion a dose of $400 \mathrm{mg} /$ day of Nigella sativa might be a beneficial adjuvant as oral hypoglycemic agents in type 2 diabetic patients, moreover this dose did not adversely affect hepatic functions throughout the study period,.
\end{abstract}

Key words: Diabetes, Nigella sativa, Salvia officinalis 


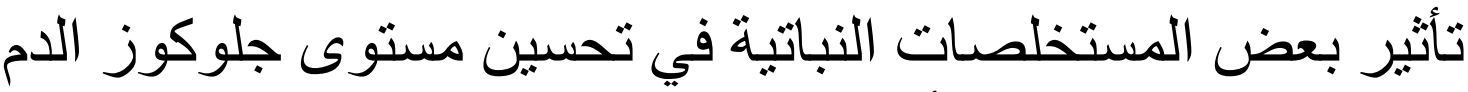

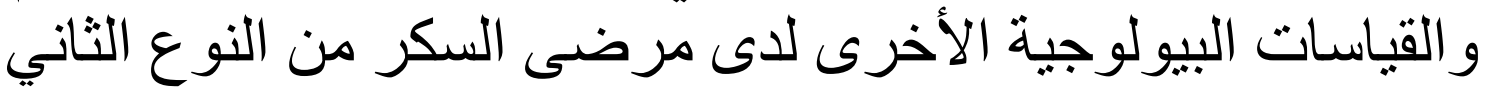

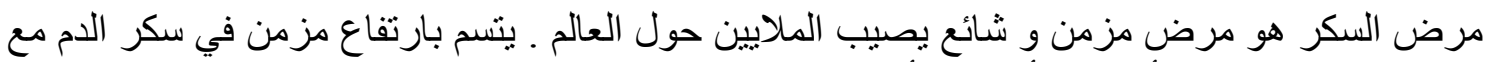

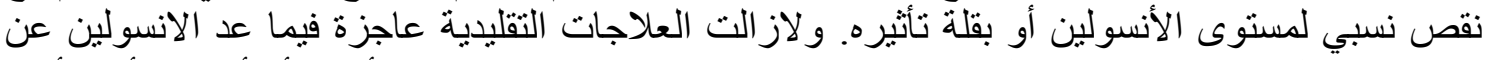

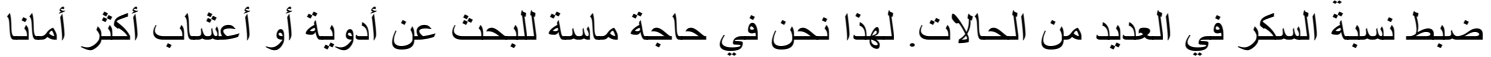

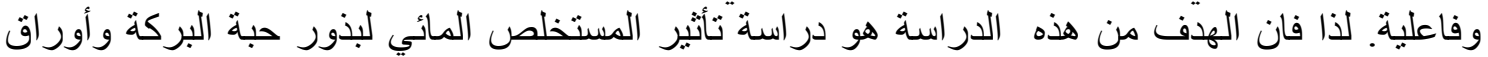

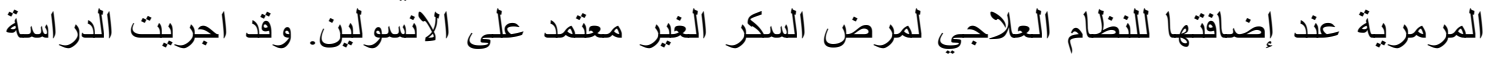

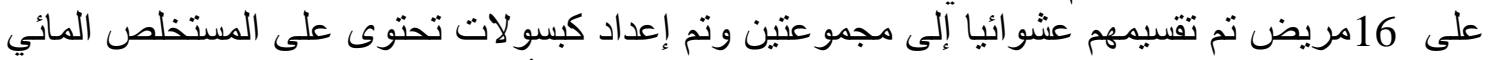

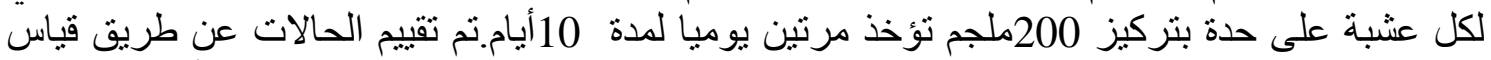

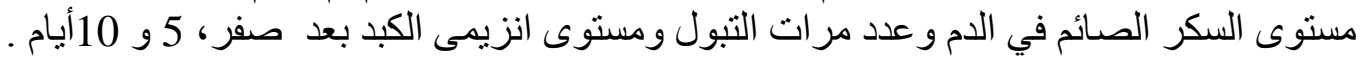

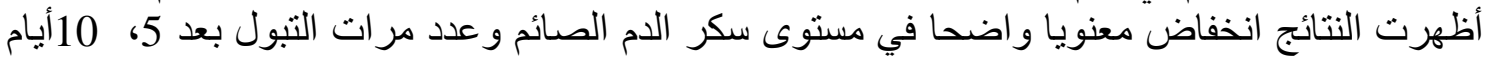

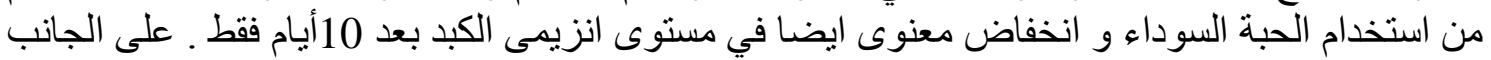

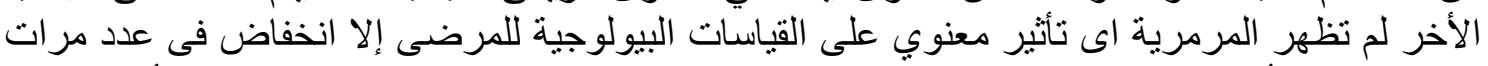

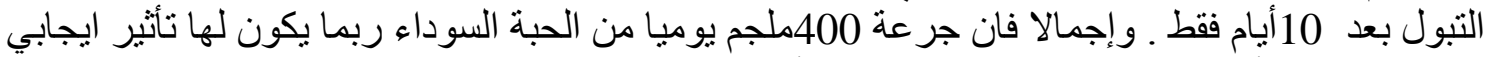

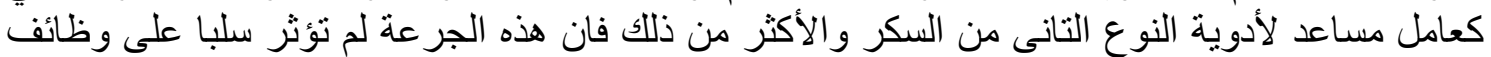
الكبد للمرضى خلال فترة الدر اسة. 


\section{Introductions}

Diabetes is a chronic disease, occurs when the pancreas does not produce enough insulin, or when the body cannot effectively use the insulin it produces. This leads to an increased concentration of glucose in the blood (hyperglycaemia). Globally, as of 2014, an estimated 387 million people have diabetes worldwide, with type 2 making up about $90 \%$ of the cases (IDF, 2014 andWHO, 2014).

Generally, diabetes is classified to two main types: type-1 diabetes (insulin-dependent diabetes mellitus) and type-2 diabetes (non-insulin-dependent diabetes mellitus). Patients with type 1 show a state of insulin deficiency because of severe defect in islet $\beta$-cell function while type 2 is characterized by a combination of resistance to action of insulin and insufficiency in insulin secretion (Ghorbani, 2013).

Currently, beside insulin, the most widely used medication for diabetes are oral hypoglycemic drugs including insulin sensitizers (biguanides, thiazolidinediones), insulin secretagogues (sulfonylureas, meglitinides), $\alpha$ glucosidase inhibitors, incretin agonists anddipeptidyl peptidase-4 inhibitors (Lorenzatiet al. 2010). The search for new antidiabetic agents with more effectiveness and less side effects has been continued. Medicinal plants have always been an important source for finding new remedies for human health problems. Traditionally, numerous herbs have been recommended for treatment of diabetes.

Nigella sativa $L$ seed (also called black seed) is an annual herb of the Ranunculaceae family. It contains many active like nigellone, and thymoquinone, which was isolated from the volatile oil fraction (Padhyeet al. 2008). Three flavonoid glycosides and triterpenesaponins were also identified from Nigella sativa (Dadgaret al. 2006). Many studies showed that Nigella sativa improves glycemic control and ameliorates oxidative stress in patients with type 2 diabetes mellitus. placebo controlled participant blinded clinical trial, showed that long term supplementation with Nigellasativa improves glucose homeostasis and enhances antioxidant defense system in type 2 diabetic patients treated with oral hypoglycemic drugs(Kaatabiet al.2015).

On the other hand, Salvia officinalis(also called sage) a one of the essential herbs with a savoury and slightly peppery flavor. Essential oil of sage contains cineole, borneol, and thujone. Sage leaf contains tannic acid, oleic acid, ursonic acid, ursolic acid, niacin, nicotinamide, flavones, flavonoid glycosides, cornsole, cornsolic acid, fumaric acid, chlorogenic acid, caffeic acid, and estrogenic substances (Akhondzadehet al. 2003). Sage showed an improvement in glycemic control and lipid profile in hyperlipidemic type 2 diabetic patients consuming sage leaf extract randomized placebo. it may be safe and have antihyperglycemic and lipid profile improving effects in hyperlipidemic type 2 diabetic patients (Kianbakht and Dabaghian, 2013).Therefore the aim of this study was to investigate the aqueous extract of Nigella sativa seeds and Salvia 
officinalis as an adjuvant therapy for patients with diabetes mellitus type 2 ,in addition to their anti-diabetic medications.

\section{Herbs:}

\section{Material and Methods}

Black seeds (Nigella sativa seeds) and sage leaf (Salvia officinalis leaf) were purchased as crude dried materials from local markets, Shbeen EL-Kom city, Monofya, Egypt. All samples were free of diseases and authenticated at faculty of pharmacology Tanta University.

Kits:

All diagnostic kits for blood glucose, Glutamic-Oxaloacetic Transaminase (GOT), Glutamic-Pyruvic Transaminase (GPT) were purchased from Bio diagnostic Co., Cairo, Egypt.

\section{Subjects:}

This study was carried out in 16out patients of both gender (4 male and 12 female) atSherbin central hospital, Mansoura, Egypt. The age of subjects ranged between 38-79 years old. All patients were suffered from diabetes type II (NIDDM). All the subjects signed a consent form before the start of study.

\section{Preparation of aqueous extract:}

Aqueous extract of two plant samples were prepared according to Elsaadanyand Rawel (2008) with small modifications. Dried samples were cleaned using kitchen paper and grinded under cooling. A $50 \mathrm{~g}$ of each powder was soaked with 1 Liter distilled water in conical flask over night at $4^{\circ} \mathrm{C}$. Soaked samples were then heated in a water bath at $60^{\circ} \mathrm{C}$ for 6 hours. Samples were left to cool at room temperature and centrifuged at $5000 \mathrm{rpm}$ then filtered using filter paper Whatman No.1. The filtrates were then dried at $45^{\circ} \mathrm{C}$ using vacuum oven. Each dried filtrates were capsulated at $200 \mathrm{mg}$ withcarboxyl methyl cellulose. All capsules were stored under cooling until use.

\section{Experimental design}

Sixteen patients divided randomly into two groups. Group1administeredgelatin capsules containing $200 \mathrm{mg}$ dried aqueous extract of Nigella sativaand carboxymethyl cellulose as filling material. Group 2: administered gelatin capsules containing $200 \mathrm{mg}$ from aqueous extract of Salvia officinalisand carboxymethyl cellulose. Blood samples were collected from patient at the morning after overnight fasting at the 0 , 5and 10 days of adminstaion.FBS, GOT and GPTwere determined according to (Schumann et al. 2002) using ELITech Clinical Systems spectrophotometer at $340 \mathrm{~nm}$.

\section{Statistical analysis:}

Data were represented as mean \pm stander deviation, significance and differences between groups were statisticallyanalyzed by (ANOVA) using Statistical Package of Social Science Program SPSS (version 21). 


\section{$\underline{\text { Results and discussion }}$}

Table (1):Effect of dried aqueous extract of black seed (Nigella sativa) and sage leaves (Salvia officinalis) on patients' fasting blood sugar and urination

frequency.

\begin{tabular}{llllllll}
\hline Groups & \multicolumn{3}{c}{ FBS(mg/dl) } & \multicolumn{3}{c}{ Urination frequency } \\
\cline { 2 - 7 } & 0 day & After 5 days & $\begin{array}{l}\text { After } \\
\text { days }\end{array}$ & $\mathbf{1 0}$ & 0 day & $\begin{array}{l}\text { After 5 } \\
\text { days }\end{array}$ & $\begin{array}{l}\text { After10 } \\
\text { days }\end{array}$ \\
\hline $\begin{array}{l}\text { Black } \\
\text { seed }\end{array}$ & $188.3 \pm 56.3$ & $161.0 \pm 23.5^{*}$ & $161.0 \pm 29.5^{*}$ & $10.0 \pm 2.6$ & $7.5 \pm 1.9^{*}$ & $7.0 \pm 1.6^{*}$ \\
Sage & $145.3 \pm 46.9$ & $156.3 \pm 65.4$ & $144.0 \pm 43.6$ & $9.0 \pm 1.6$ & $7.5 \pm 1.0$ & $6.5 \pm 1.0^{*}$ \\
\hline
\end{tabular}

Data represented as Mean \pm SD of 8 replicates.

$*(\mathrm{p} \leq 0.05)$ between 0 day and other periods.
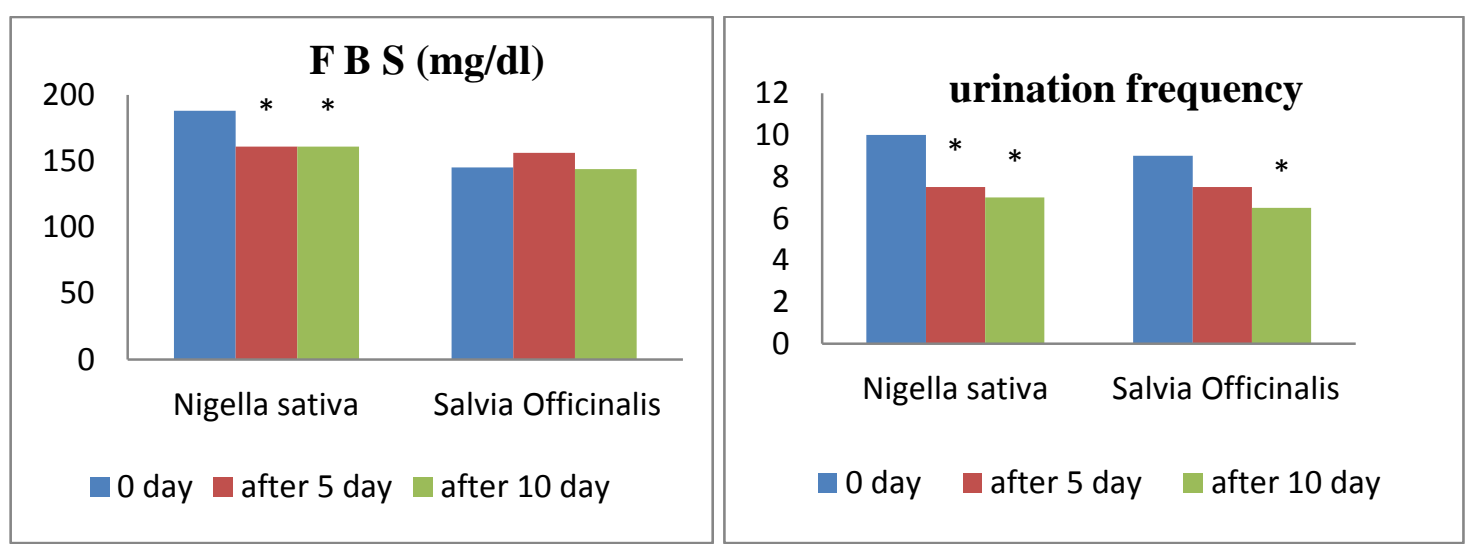

Figure (1):Effect of dried aqueous extract of black seed (Nigella sativa) and sage

leaves (Salvia officinalis) onpatients' fasting blood sugar and urination frequency.

The effect of black seed and sage on fasting blood sugar and urination frequency are presented in Table (1) and figure (1).Results showed that Nigella sativa caused significant reduction on FBG and urination frequency after 5 and 10 days. On the other hand Salvia officinalis didn't show significant effects on both parameters except of significant reduction on urination frequency after 10 days. These data was in agreement with Hawsawiet al. (2001)that $N$. sativa seeds and their active ingredient, thymoquinone, have a promising reducing effect on the blood glucose levels in normal rats. Moreover,Mohtashamiet al. (2011) showed a significant decrease in fasting blood glucose and HbA1c levels in Black seed oil treated patients as compared to control group at the end of the study. On the other hand results of sage extract were not agreed withHajzadehet al. (2011))that 4 hours after an injection of a sage waterextract, blood glucose decreased significantly in fasted normal mice and in fasted mildly alloxandiabetic mice, but not in fasted severely alloxan-diabetic mice. 
Table (2): Effect of black seed and sage on liver function

\begin{tabular}{|c|c|c|c|c|c|c|}
\hline \multirow[t]{2}{*}{ Groups } & \multicolumn{4}{|c|}{$\begin{array}{c}\text { GOT } \\
\text { (unit/l) }\end{array}$} & \multicolumn{2}{|c|}{$\begin{array}{c}\text { GPT } \\
\text { (unit/l) }\end{array}$} \\
\hline & 0 day & $\begin{array}{l}\text { After } \\
5 \text { days }\end{array}$ & $\begin{array}{l}\text { After } \\
10 \text { days }\end{array}$ & 0 day & $\begin{array}{ll}\text { After } & 5 \\
\text { days } & \end{array}$ & $\begin{array}{ll}\text { After } & 10 \\
\text { days } & \end{array}$ \\
\hline $\begin{array}{l}\text { Black } \\
\text { seed }\end{array}$ & $34.8 \pm 18.3$ & $\begin{array}{l}33.5 \pm \\
7.7\end{array}$ & $\begin{array}{l}30.5 \pm \\
9.7 *\end{array}$ & $37.0 \pm 16.1$ & $34.0 \pm 15.3$ & $29.0 \pm 14.7 *$ \\
\hline Sage & $33.5 \pm 9.0$ & $\begin{array}{l}30.3 \pm \\
7.1\end{array}$ & $\begin{array}{l}33.5 \pm \\
9.0\end{array}$ & $29.5 \pm 13.8$ & $9.1^{25.5 \pm}$ & $28.8 \pm 13.8$ \\
\hline
\end{tabular}

Data represented as Mean \pm SD of 8 replicates.

$*(p \leq 0.05)$ between 0 day and other periods.
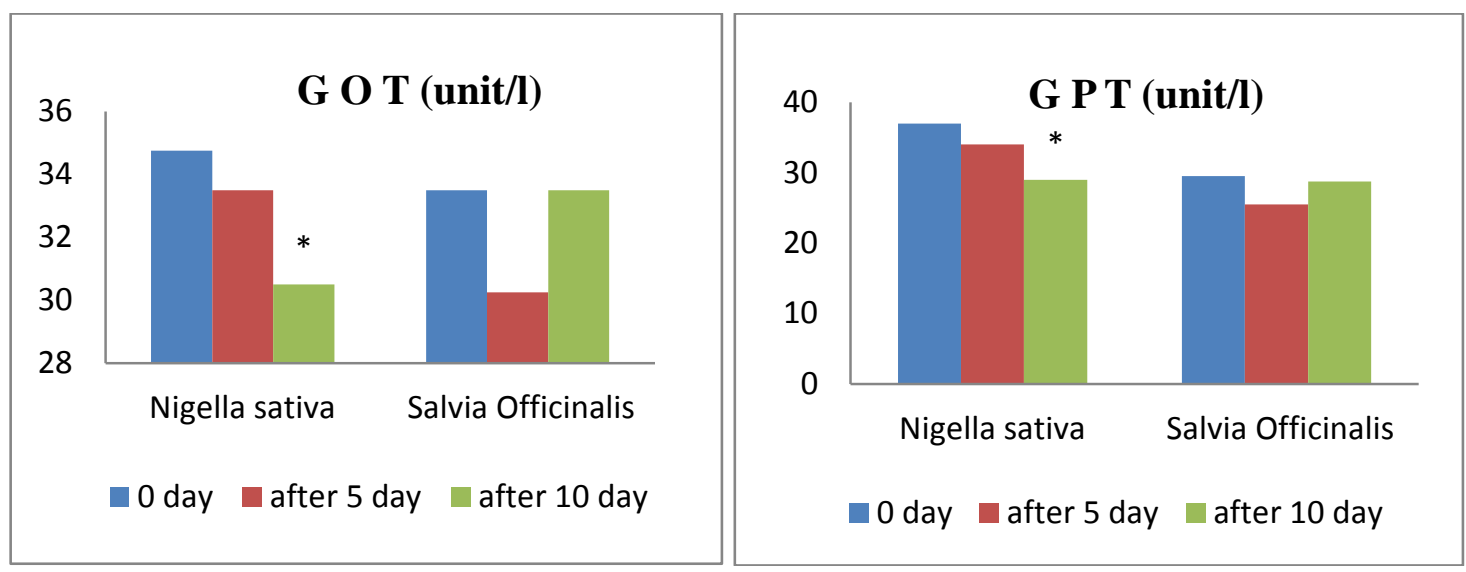

Figure (2):Effect of dried aqueous extract of black seed (Nigella sativa) and sage leaves (Salvia officinalis) on liver enzymes.

Effects of black seed and sage on liver enzymes are presented in Table (2) and figure (2).As shown GOT and GPT are significantlyreduced or attenuated to normal levels after 10 days by black seed.On the other hand,sagedidn't show significant effects after 5 or 10 days. These results also confirmed that both plants have no significant hazards on the liver.These results are in agreement with Kushwahet al. (2014) that black seed pretreatment significantly prevented the increase in liver enzymes and total bilirubin and decrease in GSH level in rats. On the other hand,Al-Khafaji (2014) showed a significant increase $(\mathrm{p} \leq$ 0.05) in GOT, GPT and total protein as compared with control occurred by black seed. Results of sage are agreement with Arabi et al. (2014) that plasma concentrations of protein, albumin and creatinine significantly increase where liver enzymes significant decrease.

The mechanism of the hypoglycemic effect of black seed has been suggested to be due to pancreatic actions via enhancing insulin secretion and inducing $\beta$-cell proliferation and regeneration (Kaatabi and Bamosa , 2015). Black seed may also improves systemic glucose homeostasis in diabetic by acting through increasing circulating insulin and enhancing the sensitivity of peripheral tissues 


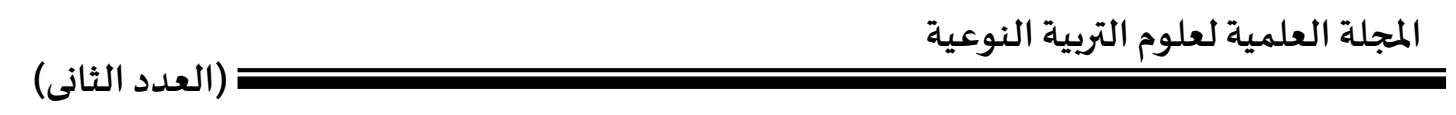

to the hormone. They attributed this effect, in part, to an activation of the AMPK pathway in skeletal muscle and liver; and to an increased content of Glut4 in skeletal muscle(Bamosa and Kaatabi et al., 2015).

In the present study.It was concluded that a dose of $400 \mathrm{mg} /$ day of Nigella sativamight be a beneficial adjuvant as oral hypoglycemic agents in type 2 diabetic patients moreover this dose did not adversely affect hepatic functions throughout the study period. 


\section{$\underline{\text { References }}$}

Akhondzadeh, S;Noroozian, M; Mohammadi, M; Ohadinia, S; Jamshidi, A.H and Khani, M. (2003). Salvia officinalis extract in the treatment of patients with mild to moderate Alzheimer's disease: a double blind, randomized and placebo-controlled trial. J Clin Pharm Ther., 28 (1): 53-9.

Al-Khafaji. Mahdi. Nada. (2014).Protective effect of crude oil of Nigella Sativa on liver in male albino mice treated with low toxic dose of paracetamol. Medical Journal of Babylon., 10:4

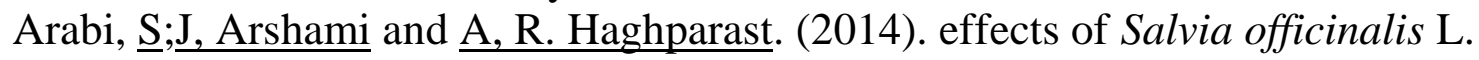
extract on biochemical blood parameters in male rats.zums.ac.ir journa., 22 (94).

Bamosa, A., H. Kaatabi, et al. (2015). Nigella sativa: A potential natural protective agent against cardiac dysfunction in patients with type 2 diabetes mellitus. J Family Community Med 22(2): 88-95.

Dadgar, T; Asmar, M; Saifi, A; Mazandarani, M; Bayat, H; Moradi, A; Bazueri, $M$ and Ghaemi, E. (2006).Antibacterial activity of certain Iranian medicinal plants against methicilin-resistant and sensitive Staphylococcus aureus. Asian Journal of Plant Sciences, (5): 861-866.

ElSaadany, M. A and H. M. Rawel. (2008). Antioxidants modulate the IL-6 induced inhibition of negative acute-phase protein secretion in HepG2 cells. Cell BiochemFunct, 26(1): 95-101.

Ghorbani, A. (2013). Best herbs for managing diabetes: A review of clinical studies. Brazilian Journal of Pharmaceutical Sciences., 49 (3): 1-20.

Hajzadeh, M.A.R; Z. Rajaei; G. Ghamami and A. Tamiz. (2011).The effect of Salvia officinalis leaf extract on blood glucose in streptozotocin-diabetic rats. Pharmacologyonline .,1: 213-220

Hawsawi, Z. A; B. A. Ali and A. O. Bamosa. (2001). Effect of Nigella sativa (black seed) and thymoquinone on blood glucose in albino rats. Annals of SaudiMedicine, 21 (5): 3-4.

International Diabetes Foundation: Diabetes Atlas. Retrieved 4 April 2014.

Kaatabi, H and A, O. Bamosa. (2015). Nigella sativa improves glycemic control and ameliorates oxidative stress in patients with type 2 diabetes mellitus: placebo controlled participant blinded clinical trial".PLoS One, 10(2): e0113486.

Kianbakht, S and Dabaghian, F.H. (2013). Improved glycemic control and lipid profile in hyperlipidemic type 2 diabetic patients consuming Salvia officinalis L. leaf extract: a randomized placebo. Controlled clinical trial. Complement". Ther Med.,21(5):441-6.

Kushwah .D.S, Salman,M.T., Singh,P. Verma,V.K. and Ahmad,A.(2014). Protective effects of ethanolicextract of Nigella sativa seed in paracetamolinduced acute hepatotoxicity In vivo. Pakistan Journal of Biological Sciences, 17: 517-522. 
Lorenzati, B; Zucco, C; Miglietta, S; Lamberti, F and Bruno, G. (2010). Oral hypoglycemic drugs: pathophysiological basis of their mechanism of action. Pharmaceuticals., 3:3005-3020.

Mohtashami, R; Amini, M;Fallah. Huseini, H; Ghamarchehre, M;Sadeqhi, Z;Hajiagaee, R and Fallah. Huseini, A. (2011). Blood glucose lowering effects of Nigella Sativa L. seeds oil in healthy volunteers: a Randomized, Double-Blind, Placebo-Controlled Clinical Trial. Journal of Medicinal Plants, 10 (39).

Padhye, S; Banerjee, S; Ahmad, A; Mohammad, R and Sarkar, F.H.(2008). From here to eternity-the secret of Pharaohs: Therapeutic potential of black cumin seeds and beyond. Cancer Ther, 6(b):495-510.

World Health Organization. Retrieved 4 April 2014. 